Running Head: DIVERSITY AS A MULTILEVEL CONSTRUCT

\author{
Ethnic Diversity as a Multilevel Construct: \\ The Combined Effects of Dissimilarity, Group Diversity, \\ and Societal Status on Learning Performance in Work Groups \\ Felix C. Brodbeck \\ Ludwig-Maximilians University, Munich, Germany \\ Yves R. F. Guillaume \\ Aston Business School, Aston University, United Kingdom \\ Nick Lee \\ Aston Business School, Aston University, United Kingdom
}

\author{
Address for correspondence: \\ Prof. Dr. Felix C. Brodbeck \\ Industrial and Organizational Psychology Group, \\ Ludwig-Maximilians University, \\ 80802 Munich, Germany \\ Tel. ++ 49 (0) 89 2180-5201 \\ E-mail: brodbeck@psy.lmu.de
}




\begin{abstract}
We present a model of the multilevel effects of diversity on individual learning performance in work groups. For ethnically-diverse work groups, the model predicts that group diversity elicits either positive or negative effects on individual learning performance, depending on whether a focal individual's ethnic dissimilarity from other group members is high or low. By further considering the societal status of an individual's ethnic origin within society (Anglo versus NonAnglo for our UK context), we hypothesize that the model's predictions hold more strongly for Non-Anglo group members than for Anglo group members. We test this model with data from $N$ $=412$ individuals working on a 24 -week business simulation in 87 four- to seven-person groups with varying degrees of ethnic diversity. Two of the three hypotheses derived from the model received full support and one hypothesis received partial support. Implications for theory development, methods, and practice in applied group diversity research are discussed.
\end{abstract}

Keywords: ethnic dissimilarity, group diversity, relational demographics, societal status, information-elaboration, small groups, multilevel models, individual learning, performance, minority/majority influence, business game simulation 


\section{Ethnic Diversity as a Multilevel Construct:}

The Combined Effects of Dissimilarity, Group Diversity, and Societal Status on Learning Performance in Work Groups

The belief that diversity among group members is beneficial for group work requiring the sharing and integration of knowledge and skill for problem solving, decision making, and individual learning has become more and more popular (e.g., Brodbeck, Kerschreiter, Mojzisch, \& Schulz-Hardt, 2007; van Knippenberg, De Dreu, \& Homan, 2004). However, robust conclusions have proven elusive (van Knippenberg \& Schippers, 2007; Williams \& O’Reilly, 1998). In particular, diversity in ethnic origin has been shown to relate positively and negatively to group functioning and performance in organizational and educational settings (e.g., Antonio et al., 2004; Chatman and Flynn, 2001).

The theoretical approaches commonly used for explaining these effects make apparently contradictory predictions. The social categorization perspective suggests that at the individual level, ethnically different work group members are less socially integrated, leading ultimately to lower individual performance and well being (e.g., Flynn, Chatman \& Spataro, 2001; Chatman \& Flynn, 2001). Similarly, this perspective suggests that ethnic diversity at the group level increases conflict and decreases cohesion, leading ultimately to lower group performance (e.g., Jehn, Nortcraft \& Neale, 1999; Harrison et al., 2002). In contrast, the information/decision making perspective suggests that ethnic diversity at the group level enhances individual group members' creativity and learning by exposing them to a broader range of knowledge, and potentially divergent perspectives and opinions, and by stimulating the elaboration of taskrelevant information (e.g., Antonio et al., 2004; Dahlin, Weingart, \& Hinds, 2005). Finally, the embedded intergroup relations perspective suggests that ethnically-diverse work groups are 
embedded in the wider societal context in which they operate, and that the distribution of power and status across ethnic groups in this wider societal context affects the way members in ethnically diverse work groups interact with each other, and accordingly affects how members perform and learn from each other (e.g., Ely, Thomas, Padavic, 2007). By integrating these three perspectives within a single multilevel framework, and conceptualizing ethnic diversity at the individual, group and societal level, we seek to reconcile these apparent contradictions. In doing so, we demonstrate that both positive and negative effects of ethnic diversity on individual learning performance in work groups can occur simultaneously at different levels.

\section{Theoretical Background and Model Development}

Individual learning results from behaviors that enable individuals to obtain and process information new to them, thereby increasing their competencies and the range of options available to solve problems within a given domain (Marton \& Saljo, 1976). In work groups where members pursue shared goals and work on interdependent tasks (Hackman, 1987), individual learning performance is fostered by behaviors such as the sharing of information and insights, collective experimenting, seeking and giving feedback, asking for help, and supporting others (Brodbeck et al., 2007; Edmondson, 1999), as well as by pointing out and discussing each other's implausible assumptions and errors (Brodbeck \& Greitemeyer, 2000a, 2000b). While such learning behaviors allow group members to improve their individual learning outcomes as a consequence of interacting with each other, they also come with a 'risk'. Social interactive learning behavior may evoke embarrassment, rejection, or punishment (Argyris, 1985), and consequently the belief that a work group is not a safe forum for personal exploration, which reduces engagement in learning behaviors (Edmondson, 1999). Thus, learning via social 
interactive elaboration in work groups is a double-edged sword, with the potential to gain information, but also to suffer from emotional harm and motivation loss.

The rationale for choosing individual learning performance as the main dependent variable in the present empirical study is fourfold. First, with a multi-level model that focuses on individual rather than group performance outcomes, clear distinctions of the relative contributions of individual-, group-, and societal-level diversity on performance outcomes can be obtained (Klein, Dansereau \& Hall, 1994). Second, while a broad consensus exists that diversity has negative effects on group functioning, and on related variables such as social integration and cohesion (e.g., Jehn et al., 1999; Harrison et al., 2002), it is on information-elaboration related outcomes such as individual learning, that positive and negative effects of diversity can theoretically occur simultaneously (van Knippenberg et al., 2004). Third, the quality of individual information-elaboration during group performance can be measured on the basis of the respective quality in individual learning outcomes. This is shown, for example, in the literature on majority and minority influence (Martin, Hewstone, Martin, \& Gardikiotis, in press), and that on cooperative learning theory (Johnson \& Johnson, 1999). Finally, one of the key criteria for evaluating the effectiveness of work groups is the extent to which they contribute positively to the learning of individual group members (Hackman, 1987), even more so for groups that are also designed to facilitate the learning of individual group members, such as student project teams (Johnson \& Johnson, 1999).

We focus on ethnic diversity because ethnic origin is among the most salient individual characteristics in organizational and educational settings (Jackson, May, \& Whitney, 1995). Ethnic origin refers here to a cluster of individual characteristics such as physical appearance, national origin, language and religion, as well as the sharing of cultural identity, values, attitudes, 
and behaviors (Phinney, 1996). As such, ethnic origin is both a surface-level diversity characteristic which is readily visible to others (Riordan, 2000), and a deep-level diversity characteristic, because differences in ethnic background are often related to differences in worldviews and perspectives (Alderfer \& Smith, 1982), norms, values, and goals (Thomas, Ravlin, \& Wallace, 1996), and reasoning and thinking styles (Nisbett, Peng, Choi, \& Norenzayan, 2001; Peng \& Nisbett, 1999), which do not become visible to others until repeated social interaction has occurred.

To explain the effects of ethnic diversity on individual learning performance we integrate the social categorization perspective, the information/decision making perspective, and the embedded intergroup relations perspective, within a single multi-level framework. In doing so we hope to reconcile the contradictory predictions made by each single perspective, and explain why and how positive and negative effects of ethnic diversity on individual learning performance can occur simultaneously. Within the social categorization perspective we conceptualize ethnic differences at the individual level as ethnic dissimilarity. Within the information/decision making perspective we conceptualize ethnic differences at the group level as ethnic diversity. Within the embedded intergroup relations perspective we conceptualize ethnic differences at the societal level as status differences between ethnic groups. Accordingly, we predict cross-level interaction effects between a) individual-level ethnic dissimilarity, b) group -level ethnic diversity, and c) societal-level status attributed to individuals of a certain ethnic origin, on individual learning performance in work groups, as depicted in Figure 1.

Insert Figure 1 about here

Ethnic Dissimilarity and Individual Learning 
At the individual level, differences in ethnic background between a focal group member and his or her peers are referred to as ethnic dissimilarity (Riordan, 2000; Tsui \& Gutek, 1999). According to self-categorization theory (Turner, 1987) people categorize themselves as similar or different from others based on salient social categories. In ethnically diverse work groups, members are therefore likely to define and differentiate themselves from others on the basis of their ethnicity (Tsui \& Gutek, 1999). According to social identity theory (Tajfel, 1981; Tajfel \& Turner, 1986) individuals are more likely to positively evaluate and identify with others who belong to the same social category, because they are motivated to maintain or enhance their social identities. Accordingly, ethnically different group members are more likely to experience negative affective-evaluative reactions from their peers (Tsui \& Gutek, 1999), and are therefore more likely to experience negative affect, feelings of anxiety, low self-esteem (Ellemers, Spears, \& Doosje, 2002), and low psychological safety (Edmondson, 1999). Under such conditions ethnically different group members should be less likely to engage in ('risky') learning behaviors, such as asking for help or publicly experimenting, than group members who share their ethnicity with several others within their work group.

\section{Group Diversity in Ethnic Origin and Individual Learning}

At the group level, differences in ethnic background are conceptualized as work group diversity (e.g., Harrison \& Klein, 2007; van Knippenberg \& Schippers, 2007). We adopt Harrison and Klein's (2007) inclusive stance, defining work group diversity here as the distribution of differences among the members of a work group in terms of ethnicity. In general, work groups provide the basis for sharing a wider array of cognitive resources among individual group members (e.g., Brodbeck et al., 2007; Jackson et al., 1995). Group diversity in ethnic background is known to result in differences in worldviews, cultural norms and preferences 
(Alderfer \& Smith, 1982; Cramton \& Hinds, 2004), cognitive orientations (Choi, Nisbett, \& Norenzayan, 1999), forms of reasoning (Peng \& Nisbett, 1999), causal attribution styles, and logical analysis (Nisbett et al., 2001). Furthermore, evidence from experimental and field studies shows that exposure to multiple cultures can enhance insight, learning, remote association and idea generation (Leung et al., 2008), integrative complexity (Antonio et al., 2004), and information elaboration (Dahlin et al., 2005). ${ }^{1}$

\section{Cross-Level Interaction between Ethnic Dissimilarity and Group Diversity}

So far we have suggested that high-diversity groups, due to higher numbers of ethnicallydifferent group members, provide more knowledge and perspectives to the potential benefit of all group members (e.g., Antonio et al., 2004; Dahlin et al., 2005). We have also suggested that within groups, ethnically-dissimilar group members are less likely than ethnically-similar group members to engage in ('risky') learning behaviours, because they are more likely to encounter negative affective-evaluative reactions from their peers (Tsui \& Gutek, 1999). As learning gains are particularly likely in high-diversity groups, learning performance differentials between ethnically-similar and ethnically-dissimilar members should therefore be more pronounced in high-diversity groups than in low-diversity groups. In other words we would expect group level diversity to interact with individual ethnic dissimilarity in that group members low in ethnic dissimilarity, when compared to group members high in ethnic dissimilarity, are better able to exploit the richer learning resources in high-diversity groups. These differences should be less pronounced in low-diversity groups due to the poorer learning resources in these groups. Societal Status of Ethnic Origin and Individual Learning

At the societal level, differences in ethnic background are conceptualized as status differences stemming from the wider societal context and socialization experiences (Ely et al., 
2007). Testing our theoretical model with a regionally-characteristic and ecologically-valid mix of ethnic groups requires explicit consideration of societal-level ethnic diversity in hypothesis formation, due to the unavoidably 'embedded' inter-group relations (Alderfer \& Smith, 1982; Alderfer, 1987). Embedded inter-group relations describe societal-level status and power differences between ethnic groups in a given society, which can create asymmetries in interpersonal experiences that impact on social interaction and individual performance in groups.

In line with status characteristics theory (Berger et al., 1977), it is suggested that in order to determine their peers' ability to promote the group's goals, work group members form (on the basis of perceived status differences) an implicit order of performance expectations for their peers. The greater the expectation advantage of one group member over another, the more likely the first group member's suggestions are evaluated positively, and the more likely he or she is to be supported even when disagreements develop. Furthermore, Ely et al. (2007) asserts that status disparities between ethnic groups in North American society are associated with expectations about ability and competence, and that ethnic minorities (e.g., Hispanic or Black American) are believed to be less competent than their white counterparts. It follows that membership in a high status ethnic group should safeguard ethnically different work group members against negative evaluative-affective reactions of their peers; while membership in a lower status ethnic group should amplify these negative evaluative-affective reactions. Thus, ethnically different members of high status ethnic groups are more likely than members of low status ethnic groups to perceive their work group to be a safe learning environment, and therefore are more likely to engage in risky learning behaviors.

From a social identity perspective, such power and status differences should also have an effect on group members' willingness to learn from each other. Members of the higher status 
ethnic group in a society maintain a positive social identity by conceptualizing members of other ethnic 'out-groups' as inferior (Tajfel, 1981; Tajfel \& Turner, 1986). Thus, they are likely to perceive knowledge, perspectives, and information put forward by members of these ethnic groups as less valid, and thus, they are less likely to learn from them. This social identity effect should not hold for members of the lower status ethnic group in a given societal context, because they are naturally interested in being part of, or at least in complying with or being accepted in, the dominant societal culture that they are studying or working in. ${ }^{2}$

\section{Hypotheses}

In the present research setting, an international Business School located in the United Kingdom, the dominant societal ethnic group consists of White British (61\%) home students (here termed Anglo). Other large ethnic groups in the student sample are Indian (19\%) and Pakistani (5\%), most of whom are British citizens in the second or third generation (here termed Non-Anglo). Also present are international students, with Chinese (5\%) as well as Arabic, Asian, Black African, Black Caribbean, and European (Finish, French, Greek, Irish, Lithuanian, Norwegian, Russian) ethnic backgrounds evident (altogether about 9\% and also termed NonAnglo).

Although our research context, with a mix of White British, Non-White British and mixed White and Non-White international students, is not the same as the North American ethnic mix which Ely et al. (2007) studied, similar status and power differentials exist between the ethnic groups studied in our UK-based sample (cf. Condor, Gibson, \& Abell, 2006). That said, for the specific group of international students, not permanently resident in the UK, the argumentation from Ely et al. may not fully apply. However, similar status differentials between White British and international students have been reported (Krahe et al., 2005). In fact our own 
observations from teaching this particular ethnic mix of students corroborates Condor et al.'s (2006) and Krahe et al.'s (2005) propositions. For example, especially during the first 10-20 weeks of studying, group discussions and in class group presentations tend to be dominated by white UK students as compared to either UK minority students or international students (European and non-European). We therefore expect that the previously-discussed effects on individual learning outcomes of individual dissimilarity and group diversity, and the interaction between these two predictors, should be more pronounced for Non-Anglo students (i.e. nonWhite British and international students) than for Anglo students. Accordingly we suggest the following three hypotheses:

First, Non-Anglo students should be more vulnerable to the negative effects of high dissimilarity on individual learning outcomes than Anglo students, because they are less likely to perceive their work group to be a safe forum for learning and interpersonal risk taking as was described above.

Hypothesis 1: There is a negative relationship between individual level ethnic dissimilarity and individual learning outcome, and this relationship is more pronounced for Non-Anglo students than for Anglo students.

Second, with increasing group diversity there should be more group resources available, from which both Non-Anglo and Anglo students can potentially profit. However, Anglo students are less likely to actually profit from them as compared to Non-Anglo students, because they perceive contributions from members of most other ethnic groups as less valid. Note that with increasing group diversity, the group resources delivered by an ethnic mix of Non-Anglo students inevitably increase as well. Thus, the proportion of group resources delivered by NonAnglo students is higher in high diversity groups as compared to low diversity groups. 
Hypothesis 2: There is a positive relationship between group-level ethnic diversity on individual learning outcome, and this relationship is more pronounced for Non-Anglo students than for Anglo students.

As argued above, the proposed negative effects of ethnic dissimilarity and positive effects of group diversity on individual learning outcomes should be less pronounced for Anglo students than for Non-Anglo students. On the one side, due to their higher status, Anglo Students should be safeguarded against the negative effects of ethnic dissimilarity, and thus are more likely to engage in risky learning behaviours than the other ethnic groups. On the other hand, Anglo students are less likely to profit from higher ethnic group diversity than Non-Anglo students, because, as was also argued before, they perceive contributions from status lower group members (Non-Anglo students) as less valid. Conversely, Non-Anglo students perceive contributions from status higher work group members as more valid, but only those who are low in individual dissimilarity within their work groups are also likely to engage in risky learning behaviours. Taken together, only low-dissimilarity Non-Anglo students should benefit from ethnic group diversity as compared to all other groups.

Hypothesis 3: There is a cross-level interaction between individual level ethnic dissimilarity and group-level ethnic diversity to the greatest benefit of low dissimilarity members in high diversity groups; the interaction is more pronounced for Non-Anglo students than for Anglo students (i.e. a three-way interaction effect).

\section{Method}

\section{Sample}

Data for the study were collected within two business simulation courses held at a large international Business School in the UK over two consecutive academic years. Data were 
merged due to statistical power and construct variance considerations. ${ }^{3}$ With respect to the variables tested, the study design was identical in both academic years, The combined data set comprised 434 upper-level undergraduate students working in 88 groups. All subjects were studying business administration or related degrees (e.g., Marketing, Finance).

Ethnic background. The students' ethnic background was retrieved from the university's database with student consent. At the very beginning of their studies students were asked to indicate their country of origin and ethnic background, which was explained to the students as the primary cultural or societal setting in which they were brought up. We further assessed students' ethnic background by a self-report measure. No contradictions were found. Information was obtained for all but one participant, whose whole work group was excluded from further analysis. Ten work groups were ethnically-homogenous, in 77 groups members were from two or more different ethnic backgrounds. After excluding further individuals due to missing data on the performance and control variables, the final sample consisted of 412 individuals (average age 20 years, 217 females and 195 males) and 87 work groups. Average group size was $M=4.91$ $(S D=.86)$, and students remained in the same group for the duration of the course (24 weeks).

\section{Procedures}

Business Simulation: The EUROCAR ${ }^{\odot}$ (2005) simulation was used, which is a complex and realistic computer-based simulation of the European automobile industry. ${ }^{4}$ Student groups form a company board for group decision making and each student is assigned a different role (such as Managing, Finance, Human Resource, Production or Marketing Director). After 10 weeks students orally presented and handed in business plans. From week 12 onwards, students operated the simulation in six one-hour sessions. Every second week they received guided 
feedback by a tutor on their performance. At the end the most successful company received a prize of $£ 250$.

During the simulation period, group members had frequent opportunities to interact, meeting at least once a week for one hour to engage in the simulation or discuss their performance. Additional meetings were required, as the groups had to develop a business plan, prepare a presentation on the business plan, and write a group report. Students were graded on the basis of several group tasks (business plan, business plan presentation, group report and net profit of their company), and on one individual task (a written essay). These evaluations had a significant impact on each individual's final assessment: business plan and presentation (40\% of final mark), group report and net-profit of their company (25\% of final mark), individual essay (35\% of final mark).

Work group composition. Members were assigned by the University's administration to their work groups on a random basis with two exceptions: a) at least one high-scoring student on prior individual learning performance (on the basis of their grades in the Finance and Accounting module) had to be present in the group, and b) groups had to be heterogeneous in terms of gender. A one-way ANOVA revealed no significant between-group differences in regard to prior learning performance $(F(1,86)=.820, p=.865)$. No differences in the distribution of females versus males within the groups $(F(1,86)=.574, p=.999)$, nor on the individual learning outcome measure between males and females (male $M=62.27, S D=8.758$; female $M=62.88$, $S D=7.686 ; t(411)=-.759, p=.448)$, were evident. Thus, gender was excluded from subsequent analyses.

Measures 
Individual-level ethnic dissimilarity. On the basis of the above categorization of students' ethnic background, ethnic dissimilarity within a given work group was calculated by using Tsui, Egan and O'Reilly's (1992) relational demography $(R D)$ formula:

$$
R D=\sqrt{\left[1 / n \sum_{i}^{j}\left(\mathrm{~S}_{\mathrm{i}}-\mathrm{S}_{\mathrm{j}}\right)^{2}\right]}
$$

For categorical variables, $\mathrm{RD}$ is calculated by assigning 1 s to a focal group member, for each other member in the group he or she differs from, and 0s for each member in the group he or she is similar to, in terms of ethnic background. These values are then summed and divided by the number of all group members, and the square root is taken of the result. In our sample, relational demography varied from 0.00 (homogeneous groups) to 0.93 (high dissimilarity).

Group-level ethnic diversity. Group-level diversity was calculated on the basis of the categorization of students' ethnic backgrounds by using Blau's Index (Blau, 1977):

$$
D=\left(1-\sum_{i=1}^{k} p_{i}{ }^{2}\right)
$$

Where $p$ is the proportion of members in a particular ethnic category and $i$ is the number of different categories represented in a student group. In our sample Blau's Index ranges from 0.00 (homogeneous groups) to 0.78 (high group diversity).

Insert Figure 2 about here

The sample's data for Blau's Index scores (group level) and RD Index scores (individual level) combined are presented in Figure 2. The squares represent the fractions per group (either a minority or a majority). Different fractions from the same work group are associated with the same group diversity score. Thus, each single group is represented twice, once below the dashed 
line, and once above. The ratios of the fractions' sizes are displayed as frequency counts per ethnic category represented (e.g., 1:5, 1:4, 2:3, 1:1:3, 1:1:4 in the main body of Figure 2, and $1: 1: 1: 2,1: 1: 2: 3$, or 1:1:1:1:2 in the blown up square). Bold numbers indicate the size and the fraction type (minority or majority) for which the individual dissimilarity scores are given on the y-axis. For an example, in a group of two fractions 1:5 (i.e. a minority of one member representing ethnic category $\mathrm{X}$ and a majority of five members representing another ethnic category Y), a bold "5" indicates the positioning of the five individual dissimilarity scores for the members of the majority in that group ( 0.42 for each majority member on the y-axis). A bold "1" indicates the positioning for the one individual dissimilarity score of the relative minority in the same group ( 0.91 on the y-axis). The respective group diversity score that is associated with each of these two fractions is 0.27 ('low' on the x-axis).

It can be seen, that the measures of individual-level dissimilarity and group-level diversity are related to each other, with ethnic dissimilarity reaching the highest scores for solo numerical minority members in an otherwise highly homogeneous or highly diverse group. However, it is also discernible that a distinction between higher and lower dissimilarity scores is evident within each work group and on each level of group diversity. Members of numerical minorities within a group (above the diagonal dashed line) and numerical majorities within a group (below the diagonal line) are discernible for nearly all groups - with the exception of ethnically homogeneous groups and groups with equally sized ethnic fractions. Thus, for each level of group diversity the individual dissimilarity measure differentiates between numerical minorities and majorities. Note that individual differences in ethnic dissimilarity diminish with increasing group diversity. 
Societal-level ethnic status. The members' ethnic status embedded within their work group, which derives from the societal status of their ethnic origin in relation to the mix of ethnic groups in the UK, was also calculated on the basis of the above categorization of students' ethnic backgrounds. We thereby followed recommendations by Ely et al. (2007) and created a dummy variable by assigning the Anglo category to White British students and the Non-Anglo category to Non-White British and all other international students. No differences between these two groups were found on prior individual learning performance (Anglo $M=3.03, S D=1.00$; NonAnglo $M=2.99, S D=1.06 ; t(411)=-.37, p=.714)$. The prior individual learning performance measure is described in more detail below.

Individual learning performance. Individual learning performance was assessed via the grades all students obtained for their individual essays, completed four weeks after the end of the simulation sessions. Grades were retrieved from the University's database with the students' consent. The essay task comprised an analysis and discussion of the operations, functioning and performance of their company during the business game. Essays were graded with regard to content, reflexivity, use of theory, exemplification, and structure of the text by several course tutors (following a blind-marking model). These essays were rated on a cumulative grade point average scale ranging from $0 \%$ to $100 \%(>70 \%=\mathrm{A}, 60 \%-69 \%=\mathrm{B}, 50 \%-59 \%=\mathrm{C}, 40 \%-49 \%=$ $\mathrm{D},<40 \%=$ fail $)$.

Prior individual learning performance. As prior individual learning performance may influence subsequent learning outcomes in the simulation, it had to be controlled for. For this the students' grades in the Finance and Accounting module taught prior to the business game were obtained with the students' consent. This module's content and the skills taught overlap with a 
number of the requirements of the simulation. The categorized grades from A (highest grade) to F (lowest grade) were available from university records and recoded into a numeric variable. Further control variables. Because we merged data from two consecutive cohorts we controlled for the academic year in which each of the cohorts were sampled. As the amount of available informational resources per group may also depend on the number of group members, group size was also controlled for. Furthermore, we included country of birth (dummy-coded: 0 $=$ non- $\mathrm{UK}, 1=\mathrm{UK}$ ) as a control variable in order to rule out alternative explanations based on differences in English language comprehension and intimate experience with the host country's dominant cultural background. In order to account for potential effects of group diversity on group-level performance brought about by social categorization and information exchange, we controlled for average group performance during the 24 week business game simulation on the basis of a combined measure of the separately marked group assessments described above (i.e. business plan, presentation, group report, and net-profit performance of the company).

Results

\section{Descriptive Statistics}

Descriptive statistics (including a full correlation matrix) are available from the first author upon request.

\section{Analytic Approach}

In homogeneous groups there is no within-group variance for individual dissimilarity scores. Moreover, all homogeneous groups in our sample comprise only Anglo members. Both factors together may have distorted our results when interaction effects were computed which involve low (or no) diversity groups. Therefore, we tested our hypotheses after excluding the homogenous groups. To this end, the analyses were conducted for a sub-sample excluding the 10 
homogenous groups ( $N=77$ groups, $n=364$ individuals). As a means to increase the generalizability of our findings to settings where homogeneous groups are found we also repeated our analysis including the homogenous groups ( $N=87$ groups, $n=412$ individuals). The same results hold for this sample and are available upon request from the first author.

To test our hypotheses we used multilevel analysis, because of the hierarchical data structure (i.e. individuals are nested within groups). All analyses were conducted using the HLM 6.04 program (Raudenbush, Bryk and Congdon, 2004). Prior to data analysis we grand mean centered all variables to mitigate potential problems brought about by multicollinearity (cf. Hox, 2002), and to overcome the biasing effects of different sub-sample sizes for the dichotomous variables (cf. Raudenbush \& Bryk, 2002). ). ${ }^{5}$ Following Raudenbush and Bryk's (2002) advice, we treated a level-1 predictor as fixed where there was no statistical evidence of slope heterogeneity, and when its reliability was lower than .05. This was the case for all control variables at the individual level. Following Hox (2002) we then tested the following four models:

Model 1: To justify the use of hierarchical linear modeling, we ran a one-way analysis of variance model, including no explanatory variables, and determined whether there was significant variance between groups on the individual learning outcome variable. We calculated the intra-class correlation of individual learning performance across all work groups, which represents the percentage of the total variance residing between groups. The between-group variance component accounted for $13.8 \%$ of the total variance $\left(I C C=0.138, \chi^{2}(76)=135.65, p\right.$ $<0.001$ ), which suggests that a significant amount of variance was explained by group membership. Model 2: To test model fit as a first step, we compared an intercept-as-outcome model, including all individual-level and group-level control variables, with Model 1. Model 2 had a better fit than Model $1\left(\Delta \chi^{2}=38.06, \Delta d f=6, \mathrm{p}<.001\right)$. Control variables thereby 
explained $13.2 \%$ of the total variance $(\Delta R=.132) .^{7}$ Model $3:$ We then compared an intercept-asoutcome model, including all individual- and group level control and predictor variables, with Model 2. Model 3 had a better fit than Model $2\left(\Delta \chi^{2}=24.5, \Delta d f=3, \mathrm{p}<.001\right)$. The block of main effects accounted for $4.6 \%$ of the total variance $(\triangle R=.046)$. Model 4 : Finally, we compared a random coefficient model, including all previous variables and the hypothesized interactions, with Model 3. Model 4 had the best fit of all $\left(\Delta \chi^{2}=16.99, \Delta d f=9, \mathrm{p}<.05\right)$, and thus further hypothesis testing is justified. The block of the interaction effects accounted for $3.4 \%$ of the total variance $(\triangle R=.034)$.

In order to test our hypotheses we interpreted the two-way and three-way interactions in Model 4. Because all variables have been grand mean-centered, the two-way interactions represent the interaction between the two variables at the mean of the third variable, and can be interpreted as the unique effect of the two-way interaction, when controlled for the mean of the third variable (Hox, 2002). ${ }^{8}$

\section{Hypotheses Tests}

Hypothesis 1 proposes a negative effect of individual ethnic dissimilarity on individual learning performance which is more pronounced for Non-Anglo than for Anglo students. The interaction between ethnic dissimilarity and ethnic status was significant $(\gamma=25.17, S E=9.12, \mathrm{p}$ $<.01, \Delta R=0.008)$. In order to further explore the interaction effect, following Cohen, Cohen, West, and Aiken's (2003) advice, we computed two simple regression equations using the dummy coded values of the categorical variable ethnic status (see Figure 3).

Insert Figure 3 about here 
We then conducted single slope tests according to Preacher, Curran, and Bauer (2006). While there was some support that the single slope for Non-Anglo students is negative $(\gamma=-$ 22.28, $S E=12.24, p=0.069)$, it was not significant for Anglo students $(\gamma=2.89, S E=12.24, p$ $=0.600)$. The specific values of the moderator variable at which the slopes of the regressions of individual learning performance on individual dissimilarity transits from non-significance to significance can be obtained by conducting a region of significance test (Preacher et al., 2006). For individual dissimilarity scores larger than 0.67, the differences between Anglo and NonAnglo students are significant at the .05 level (see Figure 3, non-shaded area). ${ }^{9}$ Thus, hypothesis 1 was partially supported in that for higher levels of individual dissimilarity $(>0.67)$ the individual learning performance of Non-Anglo students is significantly lower than for Anglo students.

Hypothesis 2 proposed a positive effect of group-level ethnic diversity on individual learning performance which is more pronounced for Non-Anglo students than for Anglo students. The interaction between ethnic group membership and group diversity was significant $(\gamma=-22.47, S E=11.25, \mathrm{p}<.05, \Delta R=0.01)$.

Insert Figure 4 about here

While the single slope for Non-Anglo students was significant and positive $(\gamma=16.30, S E$ $=5.26, p=0.002)$, it was not significant for Anglo students $(\gamma=-6.17, S E=4.40, p=0.161)$. Thus, hypothesis 2 was supported in that for the Non-Anglo students, individual learning performance increases with higher levels of group diversity, while there is no such increase for Anglo students. According to the region of significance test (Preacher et al., 2006) it can be seen 
in Figure 4 (non-shaded areas) that for group diversity scores smaller than 0.53 the differences between Anglo and Non-Anglo students are significant at the .05 level.

Hypothesis 3 proposed a moderating effect of group diversity on the relationship between individual dissimilarity and individual learning performance for Non-Anglo, but not for Anglo students. More specifically Hypothesis 3 predicted that Non-Anglo students perform best under conditions of low individual dissimilarity and high group diversity. The three-way interaction between ethnic status, group diversity, and individual dissimilarity was significant $(\gamma=129.63$, $S E=53.03, \mathrm{p}<.05, \Delta R=0.013)$. The two-way interactions between individual dissimilarity and group diversity are presented in Figure 5, for Non-Anglo (upper part of Figure 5) and Anglo (lower part) students.

Insert Figure 5 about here

For Non-Anglo students, the single slope of individual dissimilarity regressed on learning performance was significant and negative under conditions of high group diversity $(\gamma=-45.88$, $S E=20.37, p=.024)$, and non-significant under conditions of low group diversity $(\gamma=1.32, S E$ $=8.45, p=.876)$. In contrast, for Anglo students, group diversity seems to have only a marginal effect on the relationship between individual dissimilarity and learning performance. The single slope of individual dissimilarity regressed on learning performance was non-significant under conditions of high group diversity $(\gamma=-3.86, S E=8.33, p=.643)$, and significant and positive under conditions of low group diversity $(\gamma=9.64, S E=4.69, p=.0398)$. The region of significance tests (Preacher et al., 2006) revealed that Non-Anglo students perform significantly better in high diversity groups as compared to low diversity groups when their individual 
dissimilarity scores range between 0.41 and 0.71 . As can be seen in Figure 5 (upper part), the regression lines do not extend below a score of 0.41 , which is due to the exclusion of homogeneous groups. Differences between Anglos in high diversity and low diversity groups are significant for group members with individual dissimilarity scores larger than 0.57. Overall, Hypothesis 3 was supported in that Non-Anglos profit most under conditions of lower levels of individual dissimilarity in combination with high levels of group diversity. In contrast, Anglo students appear to perform better under conditions of high individual dissimilarity in combination with low levels of group diversity.

\section{Discussion}

A multi-level model of ethnic diversity was empirically tested. It posits that ethnic diversity in work groups can have positive and negative effects on individual learning simultaneously at the individual and group levels of analysis, and that these effects interact across levels. Furthermore, the model posits that all effects, including the interactions, are moderated by the societal-level status disparity between the dominant ethnic group and other ethnic groups of subdominant societal status, such that the expected effects are predominant for members of the sub-dominant ethnic groups.

For ethnically-diverse student work groups in a typical mix of ethnic origin at a UKbased international business school, the results obtained are in accord with the three hypotheses proposed. The model's predictions hold particularly for Non-Anglo students (i.e. those who don't belong to the dominant white British population), in that individual-level ethnic dissimilarity tends to be negatively related to the individual learning outcome (Hypothesis 1), while at the same time, group level diversity is positively related to individual learning outcome (Hypothesis 2). Both levels interact such that the highest learning outcome is shown by Non- 
Anglo majority members who score low in individual ethnic dissimilarity, and are working in high diversity groups (Hypothesis 3). In contrast, for Anglo students the respective relationships found are either substantially weaker in magnitude, non-significant, or opposite in direction.

\section{Theoretical, Practical, and Methodological Implications}

The present study's findings help to combine and extend previous group diversity and relational demography research in theoretical, practical and methodological respects. To our knowledge for the first time, it has been shown in a field setting that positive and negative effects of diversity on individual performance exist simultaneously at multiple levels, and interact across levels. Group diversity researchers have argued that negative effects of ethnic diversity are driven mainly by the social impairing of performance, and that its positive effects are driven by the provision of more variety in the exchange of perspectives and information (cf., Williams \& O’Reilly, 1998; van Knippenberg \& Schippers, 2007). Both these arguments focus on the group level of analysis. Relational demography researchers have argued that diversity (in the sense of individual dissimilarity from others within a group) generally has a negative effect on individuallevel social integration within work groups, and thus, on individual performance (e.g., Flynn et al., 2001). Finally, research on "embedded" inter-group relations suggests that societal-level status and power differences exist between ethnic groups in a given society, which create asymmetries in ethnic groups' experiences at the interpersonal level and individual performance (e.g., Alderfer \& Smith, 1982). The results obtained in our study show that, even though it can not be the case that such apparently contradictory perspectives are uniformly right, they are not individually wrong. Instead, the results of this study show that the conflicting theoretical positions can be integrated by applying a multi-level model of ethnic diversity in work groups which accounts for the relevant individual, group, and societal level aspects of ethnic diversity. 
The view that positive effects of work group diversity can be harvested when the dysfunctional effects of social categorization are overcome (e.g., van Knippenberg et al. 2004) is supported and further refined by our results. Not only is there a significant positive relationship between group-level ethnic diversity and individual learning performance for Non-Anglo students, but also an interaction effect to the highest benefit for low dissimilarity Non-Anglo students in high diversity groups. For this particular group of individuals a net gain in learning performance due to ethnic diversity was empirically shown.

Our findings also echo recent thought highlighting the importance of considering the societal status of ethnic origin when studying ethnic diversity (e.g., Chattopadhyay, Tluchowska, \& George, 2004, Ely et al., 2007). No matter where in the world researchers set out to study multiethnic group work, there is a regionally-characteristic mix of ethnic groups with pre-existing societal status differentials that must be accounted for. The results of the current study suggest that status differences can increase a group member's vulnerability to the dysfunctional effects of social categorization and related group processes, but can also facilitate a member's openness toward others' perspectives and opinions. In the current study lower-status members learnt less when ethnically different from their peers, but also profited more from higher group diversity, in particular when low in ethnic dissimilarity. Such moderator effects have rarely been studied previously, and this gap may have distorted the results reported in prior reviews of group diversity and performance. Therefore we recommend that, when testing relationships between work group diversity in ethnic origin and individual or group performance, one should account for individual-level and embedded societal-level ethnic diversity effects.

In practical terms, Non-Anglo group members show the best overall learning outcome under conditions of high ethnic group diversity, and when they also have one or more role 
partners in ethnic origin. In contrast White-Anglo students are guarded against the negative effects stemming from individual ethnic dissimilarity, but are also not able to harvest the positive effects of high levels of ethnic group diversity. From these findings it appears plausible to assume that group compositional considerations (such as finding commensurate role partners for token members), and interventions targeting individual group members (such as individual training or coaching), may need to complement whole-group interventions in order to fully harvest positive learning effects in diverse work groups. More specifically, our results suggest that Non-Anglo students should be put into highly diverse work groups in which they are in the numerical majority. While our results are inconclusive regarding how to enable White-Anglo students to harvest the positive effects of high levels of diversity, they do suggest that they are not negatively affected by high levels of individual ethnic dissimilarity. We may thus speculate that changing White-Anglo students' belief systems about the value of diversity by exposing them for instance to cultural awareness training or coaching may also enable them to more effectively harness cultural diversity for their individual learning (cf. van Dick et al., 2008). We therefore recommend that this be explored further in future research.

\section{Limitations and Generalizability}

The effect sizes that we found (about $1 \%$ explained variance, translating roughly into a correlation of .10) appear small in light of the criteria set by Cohen (1992). However, even such small effect sizes are considered important in the social sciences (McClelland \& Judd, 1993). In particular, empirical findings in the social sciences (e.g., Champoux \& Peters, 1987) suggest that effect sizes regarding moderator effects explain on average between 1-3\% of the variance. Thus, the effect sizes obtained in the present study are within the range usually found when testing for moderator effects. Moreover, closer inspection of Figure 5, for instance, reveals that the 
moderating effects are actually quite substantive in practical terms. They lead to learning outcome gains of about 20 percent for Non-Anglo high dissimilarity (55\% mark) versus NonAnglo low dissimilarity students (75\% mark), both in high diversity groups. In marking grade terms, this translates to the difference between a ' $\mathrm{C}+{ }^{\text {' }}$ and an ' $\mathrm{A}$ '.

Nevertheless, in field research spurious correlations are always possible due to uncontrolled third variables. We have taken great care to account for the different levels of analysis (see footnotes 6 and 9) and to control for known potential third variables, such as prior learning outcomes, group size, and country of birth, in order to rule out alternative explanations based on individual differences in task competency, English language comprehension, and experience with the host country's dominant culture. Considering these measures, we are confident that the effect sizes obtained are robust and constitute conservative estimates. In our study individual learning performance was measured at 24 weeks from group formation. Accordingly, time may have affected group dynamics and students' learning experiences in their groups. For instance researchers have long assumed that increased contact between members of different groups will improve intergroup relations because in-group members will learn that out-group members do not fit their negative stereotypes (cf. Flynn et al., 2001; e.g., Harrison et al., 2002). However, were our results time-dependent, status differences between the status higher and status lower ethnic groups should have been minimized over time, and members high in ethnic dissimilarity should have suffered less over time. Instead our findings corroborate previous findings in the status characteristics theory literature, that status differences are stable and barely change over time (Berger et al., 1977), and that interpersonal contact will fail to reduce negative-affective reactions towards out-groups when in-group and out-group members are of different status (Pettigrew, 1998). Nevertheless, it may be interesting 
for future research to look at the time-dependency of our results in more detail by measuring learning performance during several measure points at earlier and later stages of group development, and not only after 24 weeks.).

The findings in the present study should generalize primarily to ethnic diversity in work groups with high task and outcome interdependence, and individual learning goals rather than pure group productivity goals - unless the group productivity task requires the individual learning of new knowledge (cf. Ancona \& Caldwell, 1992). For such tasks and goals, it has been argued that positive effects of group level diversity are likely to dominate the potential negative effects (e.g., van Knippenberg et al., 2004). For reasons of conceptual clarity over the multiple levels of analysis, we have controlled for group-level performance by using separate indicators of group productivity (see methods section). Thus, we cannot present data from direct measures of group performance in relation to individual learning performance. However, it appears plausible that positive and negative effects of ethnic diversity on individual learning transfer to group level performance.

Because the effects of only one diversity variable (ethnicity) were tested, further empirical evidence is needed to demonstrate the generalizability of our multi-level model to other diversity variables, such as age, gender, professional, occupational or functional background. We could not investigate similar effects for these diversity variables in our setting, because the sample was a) systematically balanced with respect to gender, b) restricted in range with respect to age and profession (Business Administration undergraduates), and c) contained assigned functional roles as part of the business game, rather than the socialized functional roles that may have resulted in true diversity in background. Still, we believe that our model is likely to apply to other diversity-related variables more generally. It is our opinion that any diversity 
characteristic that brings about a wider pool of task-relevant cognitive resources to a work group, and at the same time elicits social categorisation processes, qualifies as a multi-level variable that can elicit positive and negative effects on performance. 


\section{References}

Alderfer, C. P., \& Smith, K. K. (1982). Studying intergroup relations embedded in organizations. Administrative Science Quarterly, 27, 35-65.

Alderfer, C.P. (1987). An intergroup perspective on group dynamics. In J. Lorsch (Ed.), Handbook of Organizational Behavior (pp.190-219). Englewood Cliffs, NJ: Prentice Hall.

Ancona, D. G., \& Caldwell, D. F. (1992). Demography and Design: Predictors of New Product Team Performance. Organization Science, 3, 321-341.

Antonio, A. L., Chang, M. J., Hakuta, K., Kenny, D. A., Levin, S., \& Milem, J. F. (2004). Effects of racial diversity on complex thinking in college students. Psychological Science, 15, 507510.

Argyris, C. (1985). Reasoning, learning, and action. San Francsico: Jossey-Bass.

Berger, J., Fisek, M. H., Norman, R. Z., \& Zelditch, M., Jr. (1977). Status characteristics and social interaction. New York: Elsevier.

Blau, P. M. (1977). Inequality and heterogeneity. New York: Free Press.

Brodbeck, F. C., \& Greitemeyer, T. (2000a). A dynamic model of group performance:

Considering the group member's capacity to learn. Group Processes and Intergroup Relations, 2, 159-182.

Brodbeck, F. C., \& Greitemeyer, T. (2000b). Effects of individual versus mixed individual and group experience in rule induction on group member learning and group performance. Journal of Experimental Social Psychology, 36, 621-648.

Brodbeck, F. C., Kerschreiter, R., Mojzisch, A., \& Schulz-Hardt, S. (2007). Group decision making under conditions of distributed knowledge: The information asymmetries model. Academy of Management Review, 32, 459-479. 
Champoux, J. E., \& Peters, W. S. (1987). Form, effect size, and power in moderated regression analysis. Journal of Occupational Psychology, 60, 243-255.

Chatman, J. A., \& Flynn, F. J. (2001). The influence of demographic heterogeneity on the emergence and consequences of cooperative norms in work teams. Academy of Management Journal, 44, 956-974.

Chattopadhyay, P., Tluchowska, M., \& George, E. (2004). Identifying the ingroup: A closer look at the influence of demographic dissimilarity on employee identity. Academy of Management Review, 29, 180-202.

Choi, I., Nisbett, R. E., \& Norenzayan, A. 1999. Causal attribution across cultures: Variation and universality. Psychological Bulletin, 125, 47-63.

Cohen, J. 1992. A power primer. Psychological Bulletin, 112: 155-159.

Cohen, J., Cohen, P., West, S., \& Aiken, L. (2003). Applied multiple regression/correlation analysis for the behavioral sciences (3rd ed.). Hillsdale, NJ: Lawrence Erlbaum Associates.

Condor, S., Gibson, S., \& Abell, J. (2006). English identity and ethnic diversity in the context of UK consituational change. Ethnicities, 6, 123-158.

Cramton, C.D., \& Hinds P. J. (2004). Subgroup dynamics in internationally distributed teams: Ethnocentrism or cross-national learning. Research in Organizational Behavior, 26, 231263.

Edmondson, A. C. (1999). Psychological safety and learning behavior in work teams. Administrative Science Quarterly, 44, 350-383.

Ellemers, N., Spears, R., \& Doosje, B. (2002). Self and social identity. Annual Review of Psychology, 53, 161-186. 
Ely, R. J., Thomas, D. A., \& Padavic, I. (2007). Team learning and the link between racial diversity and performance. Unpublished manuscript, Harvard Business School, Boston.

Enders, C. K., \& Tofighi, D. (2007). Centering predictor variables in cross-sectional multilevel models: A new look at an old issue. Psychological Methods, 12, 121-138.

Eurocar $^{\odot}$ (2005). The Orange Group Ltd. Upper Heyford, Oxfordshire, United Kingdom.

Flynn, F. J., Chatman, J. A., \& Spataro, S. E. (2001). Getting to know you: The influence of personality on impressions and performance of demographically different people in organizations. Administrative Science Quarterly, 46, 414-442.

Hackman, J. R. (1987). The design of work teams. In J. W. Lorsch (Ed.), Handbook of organizational behavior (pp. 315-342). Englewood Cliffs, NJ: Prentice-Hall.

Harrison, D. A., \& Klein, K. J. (2007). What's the difference? Diversity constructs as separation, variety or disparity in organizations. Academy of Management Review, 32, 1199-1228.

Harrison, D. A., Price, K. H., Gavin, J. H., \& Florey, A. T. (2002). Time, teams, and task performance: Changing effects of surface- and deep-level diversity on group functioning. Academy of Management Journal, 45, 1029-1045.

Hox, J. (2002). Multilevel analysis: Techniques and applications. Mahwah, NJ: Lawrence Erlbaum Associates.

Jackson, S. E., May, K. E., \& Whitney, K. (1995). Under the dynamics of diversity in decision making teams. In R. A. Guzzo \& E. Salas (Eds.), Team effectiveness and decision making in organizations (pp. 204-261). San Francisco: Jossey-Bass.

Jehn, K. A., Northcraft, G. B., \& Neale, M. A. (1999). Why differences make a difference: A field study of diversity, conflict, and performance in workgroups. Administrative Science Quarterly, 44, 741-763. 
Johnson, D. W., \& Johnson, R. (1999). Learning Together and Alone (5th ed.). Boston, MA: Allyn \& Bacon.

Klein, K. J., Dansereau, F., Hall, R.J. (1994). Level issues in theory development, data collection, and analysis. Academy of Management Review, 19, 195-229.

Krahé, B., Abraham, C., Felber, J., \& Helbig, M. K. (2005). Perceived discrimination of international visitors to universities in Germany and the UK. British Journal of Psychology, $96,263-281$.

Leung, A. K., Maddux, W. W., Galinsky, A. D., \& Chiu, C. (2008). Multicultural experience enhances creativity. The when and how. American Psychologist, 63, 169-181.

Martin, R., Hewstone, M., Martin, P. Y., \& Gardikiotis, A. (in press). Persuasion from majority and minority groups. In W. Crano \& R. Prislin (Eds.), Attitudes and Persuasion. Psychology Press.

Marton, F., \& Saljo, R. (1976). On qualitative differences in learning: I. Outcome and process. British Journal of Educational Psychology, 46, 4-11.

McClelland, G. H., \& Judd, C. M. (1993). Statistical difficulties of detecting interactions and moderator effects. Psychological Bulletin, 114, 376-390.

Nisbett, R. E., Peng, K., Choi, I., \& Norenzayan, A. (2001). Culture and systems of thought: Holistic versus analytic cognition. Psychological Review, 108, 291 - 310.

Peng, K., \& Nisbett, R. E. (1999). Culture, dialectics, and reasoning about contradiction. American Psychologist, 54, 741-754.

Pettigrew, T. F. (1998). Intergroup contact theory. Annual Review of Psychology, 49, 65-85. Phinney, J. (1996). When we talk about American Ethnic groups, what do we mean? American Psychologist, 51, 918-927. 
Preacher, K. J., Curran, P. J., \& Bauer, D. J. (2006). Computational tools for probing interaction effects in multiple linear regression, multilevel modeling, and latent curve analysis. Journal of Educational and Behavioral Statistics, 31, 437-448.

Raudenbush, S. W., \& Bryk, A. S. (2002). Hierarchichal linear models: Applications and data analysis methods. (2nd ed.). Newbury Park, CA: Sage.

Raudenbush, S., Bryk, A., \& Congdon, R. (2004). HLM 6.0. Hierarchical linear modeling and nonlinear modeling. IL: Scientific Software International.

Riordan, C. M. (2000). Relational demography within groups: Past developments, contradictions, and new directions. In G. R. Ferris (Ed.), Research in personnel and human resources management (Vol. 19, pp. 131-173). Greenwich, CT: JAI Press.

Singer, J. D. (1998). Using SAS PROC MIXED to fit multilevel models, hierarchical models, and individual growth models. Journal of Educational and Behavioral Statistics, 23, 323355.

Tajfel, H. (1981). Social psychology of intergroup relations. Annual Review of Psychology, 33, 1-39.

Tajfel, H., \& Turner, J. C. (1986). The social identity theory of intergroup behavior. In S. Worchel \& W. Austin (Eds.), Psychology of intergroup relations (pp. 7-24). Chicago: Nelson-Hall.

Thomas, D. C., Ravlin, E. C., \& Wallace, A. W. (1996). Effect of cultural diversity in work groups. Research in the Sociology of Organizations, 14, 1-33.

Tsui, A. S., \& Gutek, B. (1999). Demographic differences in organizations: Current research and future directions. Lanham, MD: Lexington Books. 
Tsui, A. S., Egan, T. D., \& O'Reilly, C. A. (1992). Being different: Relational demography and organizational attachment. Administrative Science Quarterly, 37, 549-79.

Turner, J. C. (1987). Rediscovering the social group: A social categorization theory. Oxford: Blackwell.

Van Dick, R., van Knippenberg, D., Hägele, S., Guillaume, Y. R .F., \& Brodbeck, F. C. (2008). Group diversity and group identification: The moderating role of diversity beliefs. Human Relations, 61, 1463-1492.

van Knippenberg D., De Dreu, C. K. W., \& Homan, A. C. (2004). Work group diversity and group performance: An integrative model and research agenda. Journal of Applied Psychology, 89, 1008-1022.

van Knippenberg, D., \& Schippers, M. C. (2007). Work group diversity. Annual Review of Psychology, 58, 515-541.

Wallace, C., \& Chen, G. (2006). A multilevel integration of personality, climate, self-regulation, and performance. Personnel Psychology, 56, 529-557.

Williams, K. Y., \& O'Reilly, C. A. (1998). Demography and diversity in organizations: A review of 40 years of research. Research in Organizational Behavior, 20, 77-140. 


\section{Footnotes}

${ }^{1}$ While we do acknowledge the negative effects that social categorization processes may have on all group members' learning activities as a consequence of ethnic diversity (e.g., Chatman \& Flynn, 2001), we concur with the categorization-elaboration model (van Knippenberg et al., 2004), which proposes that information-elaboration benefits of work group diversity can be harvested if the negative effects of social categorization processes are overcome or outweighed by the positive effects of information-elaboration. This is particuarly likely in work groups that pursue common goals, and that work on interdependent tasks requiring the learning of new knowledge (e.g., van Dick et al., 2008).

${ }^{2}$ While members of lower-status groups may redefine or directly challenge the superiority of the higher-status out-group, in particular when they perceive group boundaries to be impermeable, we suggest that the high task interdependence under which work groups usually operate will lead the lower-status members to perceive group boundaries to be permeable (cf. Tajfel \& Turner, 1986). Under such conditions social identity theory would actually predict that the lower-status group members will accept the superiority of the higher-status members.

${ }^{3}$ While we found no differences on the group diversity variable between the samples of the first and the second academic year (first year: $M=.40, S D=.22$; second year: $M=.47, S D=$ $.12 ; t(85)=1.35, p=.182$ ), we did find differences on ethnic dissimilarity (first sample: $M=.55$, $S D=.30 ;$ second sample: $M=0.63, S D=0.26, t(411)=2.39, p<.05)$ and individual learning performance (first sample: $M=59.87, S D=8.39$; second sample: $M=63.38, S D=7.99, t(411)$ $=3.69, p<.001)$. However, the results of separately conducted hypotheses tests per sample were the same, although due to lower power, they reached significance only when applying one-tailed tests. We merged both samples to improve power and increase variance on the focal variables. 
${ }^{4}$ For a download of a demonstration version, see

http://www.theorangegroup.com/eurocar.html

${ }^{5}$ As grand mean centering sometimes confounds cross-level interactions, or interactions involving a pair of Level 1 variables with a between group interaction (Enders \& Tofighi, 2009), we also tested a model in which we entered the aggregated means (i.e. Group Ethnic Diversity and Percentage of White-Anglos) of the individual level predictor variables (i.e. Individual Ethnic Dissimilarity and Ethnic Status) and the interactions between these aggregated means (i.e. the interaction between Group Ethnic Diversity and Percentage of White-Anglos) as group-level predictors of the intercept. We thereby treated Group Ethnic Diversity and the aggregated mean of Individual Ethnic Dissimilarity interchangeably, as they were statistically the same $(\mathrm{r}=.99)$, and accordingly entered only Group Ethnic Diversity in the equation. The pattern of results resembled the ones presented here, and neither Group Ethnic Diversity, nor Percentage of WhiteAnglos or their interaction predicted individual learning performance. Accordingly, we concluded that our results are not confounded with a between-group interaction.

${ }^{6}$ To test for multicollinearity we inspected the off-diagonals in the $\tau$-correlation matrix, as none approached 1, we concluded multicollinearity was not a problem (Raudenbush \& Bryk, 2002).

${ }^{7}$ Following Wallace and Chen (2006) we report $\Delta \mathrm{R}^{2}$ results from OLS regression analyses as a way of conveying effect sizes. We did this by assigning the scores of all grouplevel variables down to individuals within the group. This approach provides an adequate approximation of the overall $\mathrm{R}^{2}$ in individual-level outcomes that is explained by individual-level and group-level predictors (G. Chen, personal communication via e-mail, July 20, 2009). In doing so, three shortcomings of the more commonly used approach suggested by Singer (1998) 
can be overcome. These drawbacks include a) the approach frequently leads to negative variances, in particular in slope-as-outcome models (cf. Hox, 2002), b) the estimated effect sizes change if one changes the scales of the explanatory variables (cf. Hox, 2002), and c) it is not comparable with other research investigating moderator variables (cf. Wallace \& Chen, 2006).

${ }^{8}$ Thus, results for all hypotheses have been obtained after controlling for the interaction between average ethnic dissimilarity and group-level diversity. Because both measures are highly correlated (in our sample .84 [whole sample] and .64 [excluding homogenous groups]), controlling for the interaction between these two measures provides estimates for our hypotheses in which the possible spurious effects brought about by the correlation between ethnic dissimilarity and group-level diversity are accounted for.

${ }^{9}$ For ease of interpretation raw scores are presented. 


\section{Figure Captions}

Figure 1. Impact of individual ethnic dissimilarity, group ethnic diversity, and their interaction, on individual learning performance, moderated by societal-level status of ethnic group. $\mathrm{H}=$ Hypothesis.

Figure 2. Cross-tabulation of individual level ethnic dissimilarity scores and group level ethnic diversity scores (see text for further descriptions).

Figure 3. Moderating effect of ethnic status in society (Anglo versus Non Anglo) on the relationship between individual ethnic dissimilarity and individual learning performance.

Figure 4. Moderating effect of ethnic status in society (Anglo versus Non Anglo) on the relationship between group ethnic diversity and individual learning performance

Figure 5. Moderating effect of group ethnic diversity on the relationship between individual ethnic dissimilarity and individual learning performance for Anglo versus Non-Anglo students 
Diversity as a Multilevel Construct 40

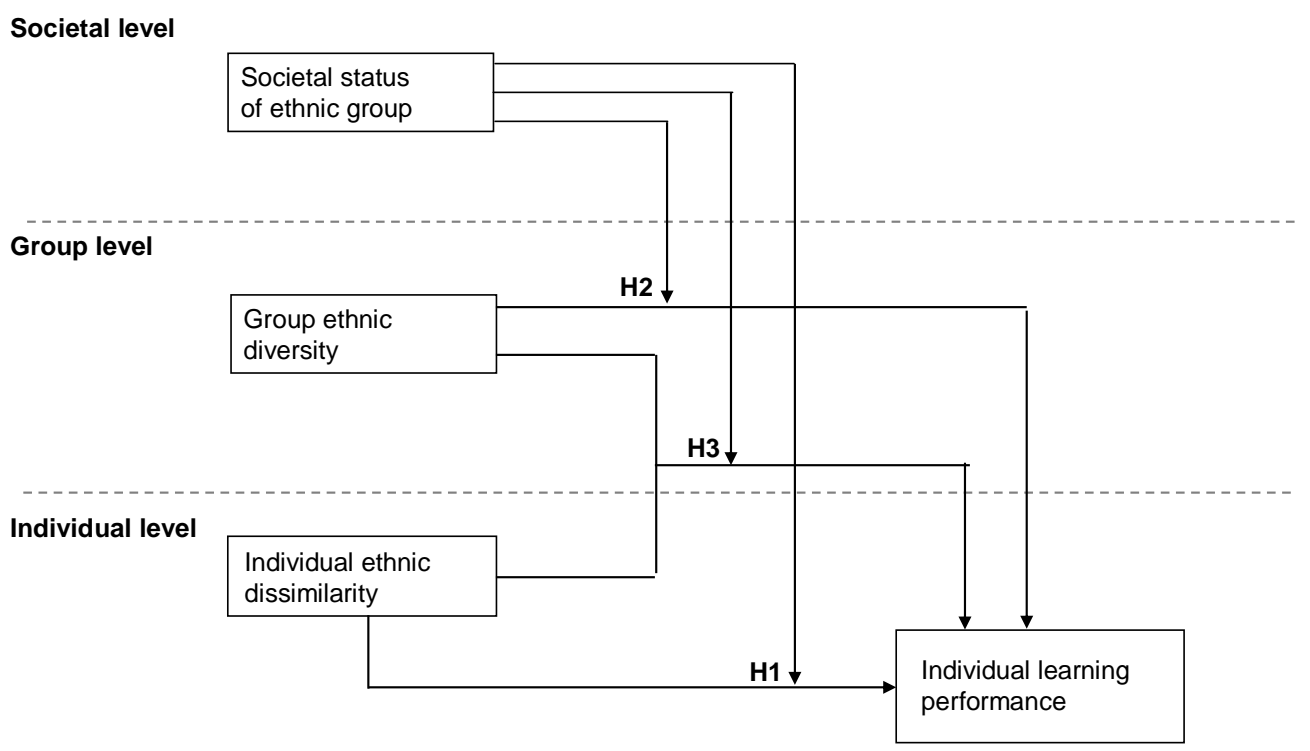




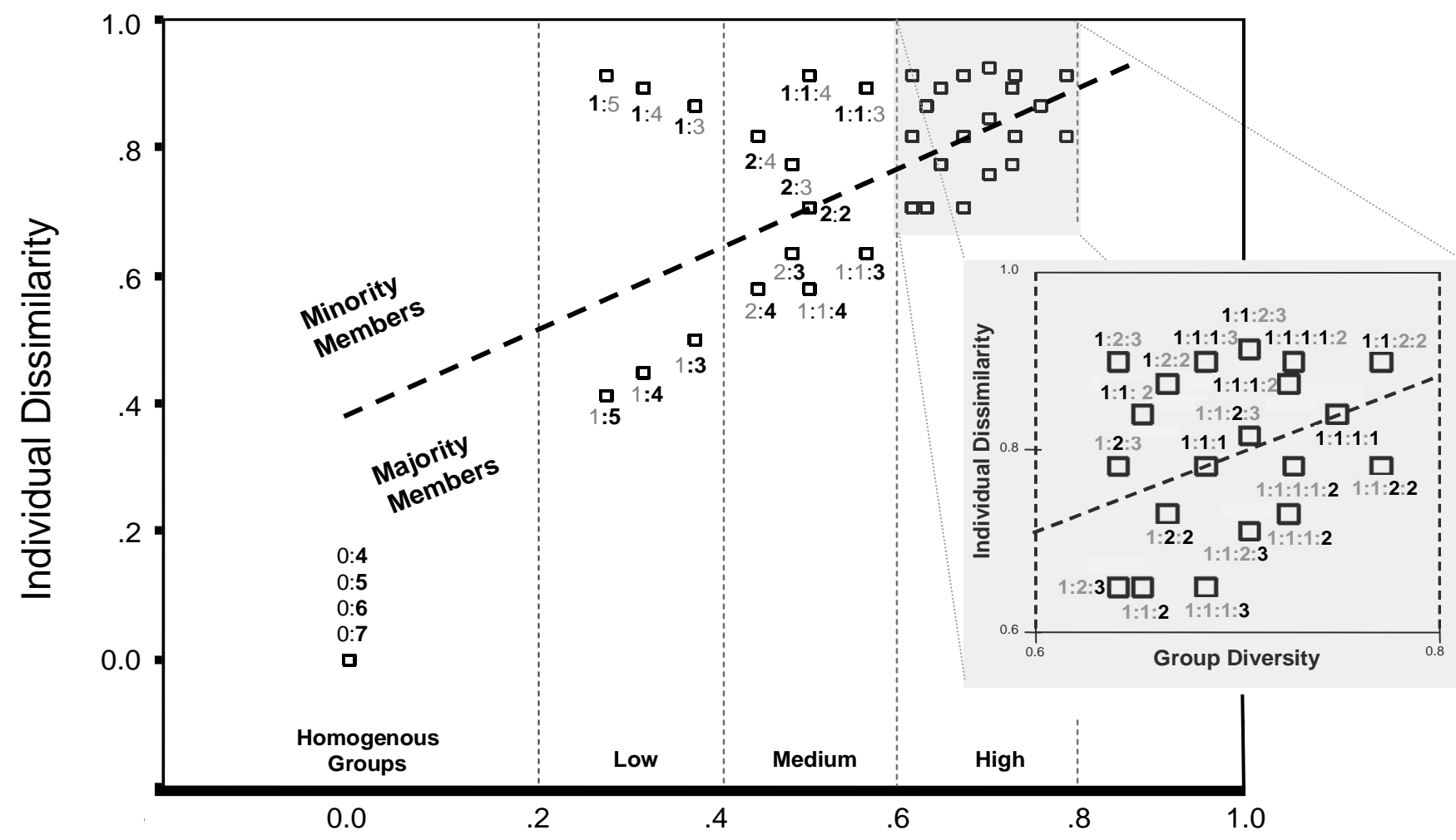

Group Diversity 


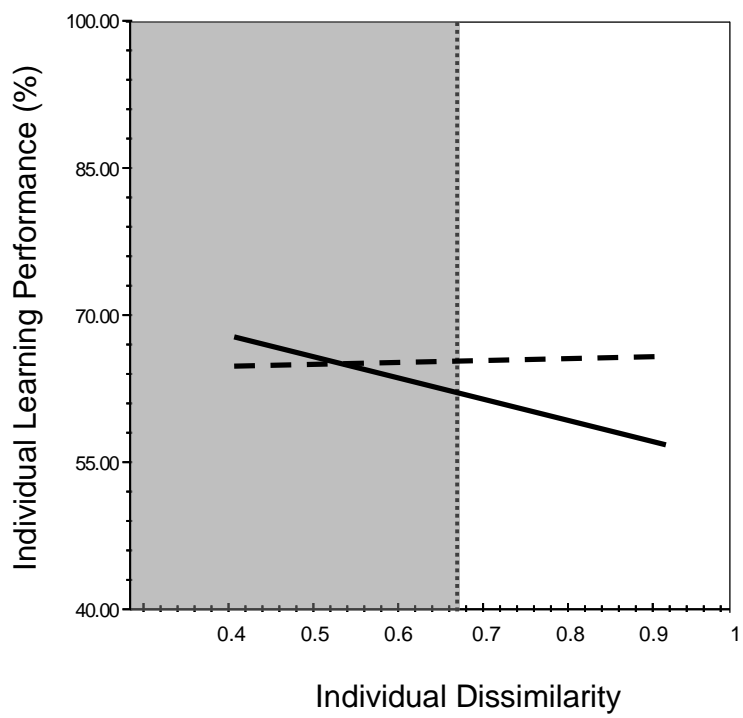

- Non-Anglo

- - - Anglo 


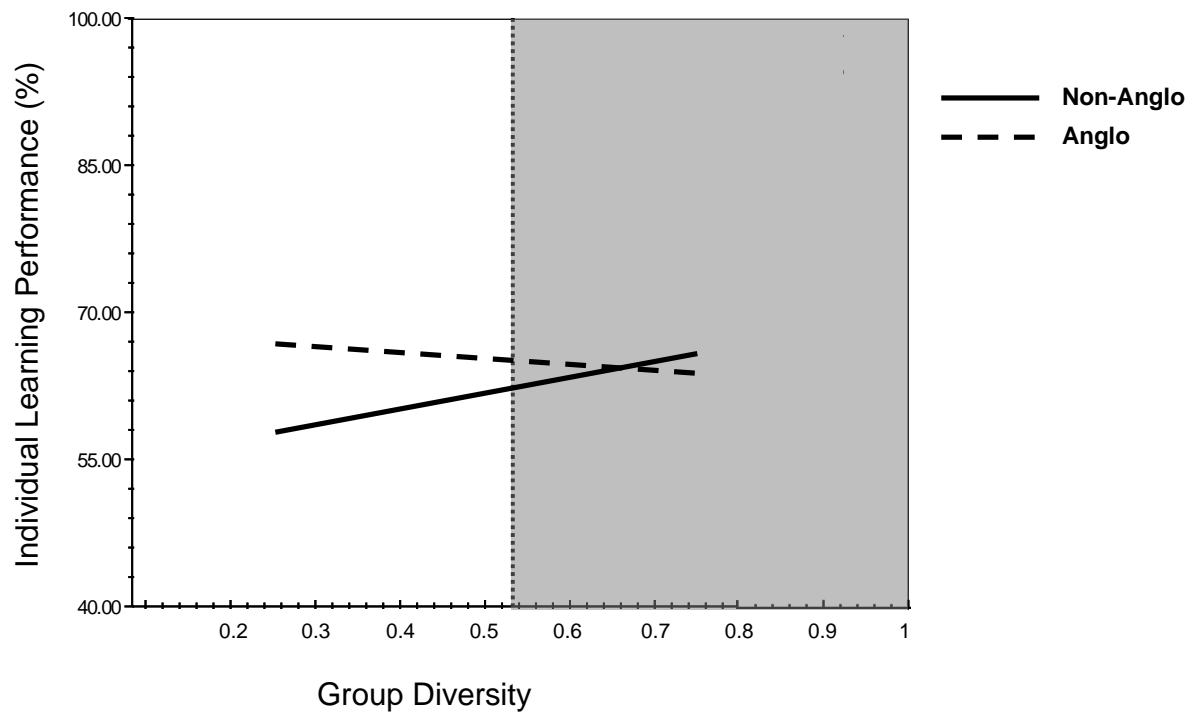


Non-Anglo

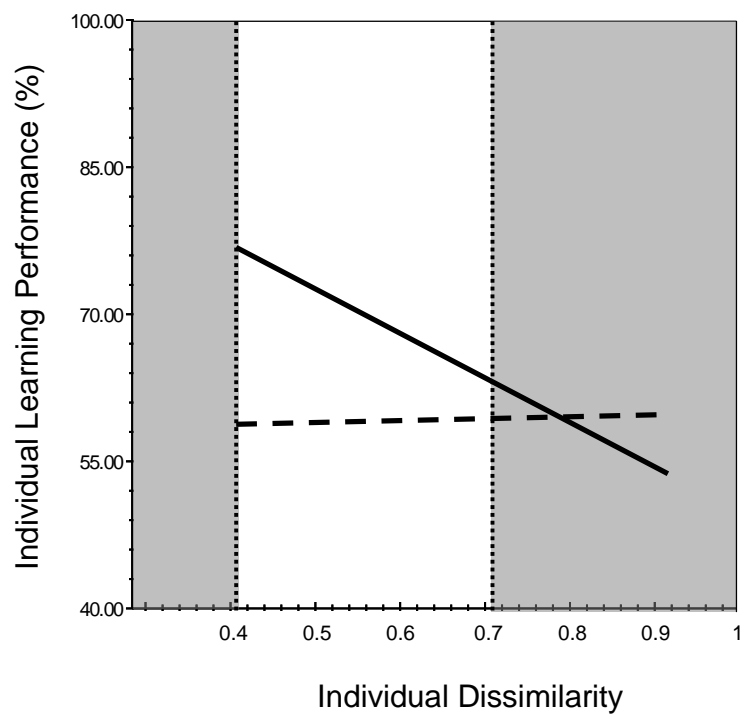

High Diversity Groups (+1 SD)

- - Low Diversity

Groups (- 1SD)
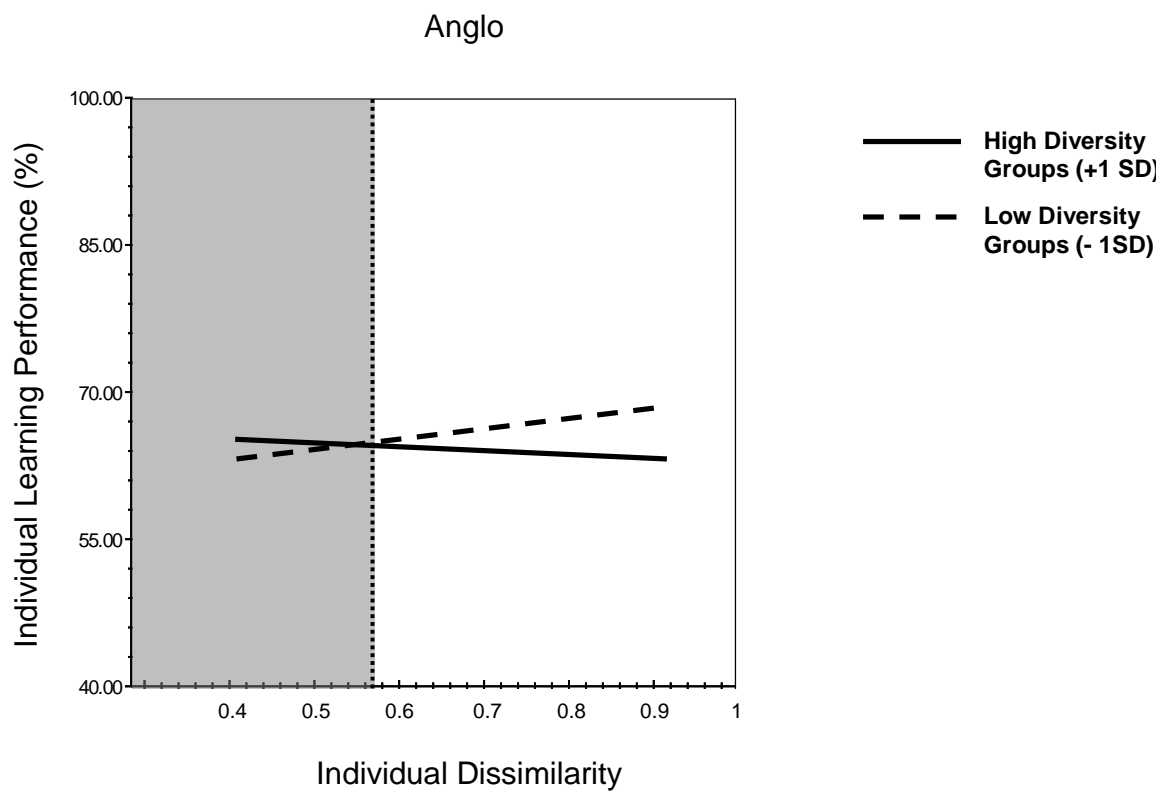

Groups (- 1SD) 